\title{
Hotelling Games with Three, Four, and More
}

Players*

\author{
Steffen Brenner ${ }^{\dagger}$ \\ (second revision)
}

October 17, 2007

\footnotetext{
*I thank Pio Baake, Helmut Bester, Nikolaj Schmuklermann, Rainer Schulz, conference and seminar participants and three anonymous referees for helpful comments. This research was supported by German National Research Center 373 "Quantifikation und Simulation ökonomischer Prozesse" at Humboldt-University, Berlin.

${ }^{\dagger}$ Humboldt-University at Berlin, School of Business and Economics, Spandauer Str. 1, D-10178 Berlin, Phone: +49.30.2093-5639, Fax:+49.30.2093-5629, e-mail: brenner@wiwi.hu-berlin.de
} 


\begin{abstract}
This paper extends the interval Hotelling model with quadratic transport costs to the $n$-player case. For a large set of locations including potential equilibrium configurations, we show for $n>2$ that firms neither maximize differentiation - as in the duopoly model - nor minimize differentiation - as in the multi-firm game with linear transport cost. Subgame perfect equilibria for games with up to nine players are characterized by a U-shaped price structure and interior corner firm locations.

Results are driven by an asymmetry between firms. Interior firms are weaker competitors than their rivals at the corners. Increasing the number of firms shifts even more power to the corner firms. As a result, there is too much differentiation from the social perspective if $n \leq 3$, while adding firms leads to a level of differentiation in equilibrium below the social optimum.

Journal of Economic Literature Classification: C72, D43, L13, R32

Key words: spatial competition, multi-player games, interval model
\end{abstract}




\section{Introduction}

The literature on Horizontal Product Differentiation focuses on the extent to which competing firms should give their products a similar design interpreted as a location in the space of product characteristics. For the two-stage model where firms choose locations in the first stage and set prices in the second stage, Hotelling (1929) acclaimed the principle of minimum differentiation. According to this principle, firms approach each other as closely as possible and share the market equally. D'Aspremont, Gabszewicz and Thisse (1979) corrected him by showing that in his model neither this strategy nor any other location choices were subgame perfect since they fail to imply an equilibrium in prices for each subgame. By altering the utility function from a linear to a quadratic form, resulting in a tougher second stage price competition, the principle of maximum differentiation could be established where firms maximize the distance to the opposite player. ${ }^{1}$

However, maximum differentiation is not as robust as some researchers initially may have believed (see, for example, Neven, 1985). Relaxing certain assumptions shifts the balance away from the centrifugal towards the centripetal forces within the model, destroying possibly the equilibrium of maximum differentiation. Several parameters have been analyzed which give rise to differentiation equilibria below the maximum level $L^{2}$ In this paper, we identify another source strengthening the

\footnotetext{
${ }^{1}$ Note that the quadratic term in the utility function measures a loss of utility.

${ }^{2}$ For example, Economides (1986) considers different utility functions. Böckem (1994), Hinloopen and van Marrewijk (1999), and Wang and Yang (1999) generalize the model on the demand side. Neven (1986) and Tabuchi and Thisse (1995) consider more general distributions of the
} 
centripetal forces, the number of firms.

Previous research has concentrated on duopoly markets. The question of how the number of firms affects the equilibrium outcome was widely ignored. Exceptions comprise Salop (1979), Novshek (1980), and Economides (1989, 1993). Linear utility models with multiple firms located on a circumference were analyzed by Salop (1979) and Economides (1989). Salop has shown that in contrast to its unit interval duopoly counterpart, price equilibria exist in the subgame characterized by an equidistance of succeeding firms. Nevertheless, a perfect equilibrium could not be found for every subgame. Economides (1993) elaborated on the similar $n$-firms interval model with linear utility. In contrast to the circular model it supports a noncooperative equilibrium in every price subgame, but fails to imply an equilibrium for the stage of the location choices. Within the class of multi-firm models with a quadratic utility function, only the circular model was analyzed. Economides (1989) proved the existence of a price equilibrium for each pattern of locations, and further, the existence of a subgame perfect equilibrium with equidistantly located firms.

Those studies revealed that the number of firms seems to have an impact on stability of the short run price game. However, no further effects regarding the location choices could be identified. On the circular domain, symmetry of all firms leads to symmetry of equilibria, given an equilibrium exists at all. Changing the consumers. Balvers and Szerb (1996) study the impact of demand uncertainty. Mai and Peng (1999) focus on the information exchange through communication and Fujita and Thisse (1986) investigate on endogenous household locations. Below maximimum differentiation equilibria even appear in the model considered by D'Aspremont, Gabszewicz and Thisse (1979) if one permits mixed strategy Nash equilibria (Bester et al., 1996). 
number of firms cannot qualitatively change equilibrium outcomes, or the degree of differentiation in the different market segments. Further, no locational equilibrium exists for the interval model with linear disutility as described by Economides (1993). Elaborating on the interval model with quadratic disutility may lead to new insights on the relation between the number of players and the degree of differentiation. Finally, in contrast to circular models, an analysis of the linear market may prove useful because the linear space or product characteristics may be of more empirical relevance.

Essentially, in Hotelling games differentiation is driven by a trade-off between the short-run and the long-run effects of relocation. In the short-run, firms may attract new customers by moving towards a competitor's position. The strategic effect is a lower price for both, the aggressor and the stationary firm because of increased competition. Which of both effects dominates depends on the model setup. In the duopoly game with a quadratic utility function, firms locate at the interval borders. One may expect a similar behavior when the number of firms increases. One of the main results of the paper is that in multi-player games, maximum differentiation is not an equilibrium. Introducing interior firms creates asymmetry in the game regarding the willingness of firms to cut prices as a response to marginal relocations by their neighbors. This holds because a price cut by an interior firm would not only affect the aggressive rival but the other neighbor too (in contrast to price cuts by corner firms). An interior firm would provoke a response from the neighbor on the opposite side, making it a weaker competitor. Economides' (1993) analysis of the corresponding game with linear disutility shows that the weakness of interior firms 
leads to the so-called "strong principle of minimum differentiation". We show, that quadratic disutility prevents firms from choosing the same location in equilibrium. Hence, neither maximum nor minimum differentiation can ever be an equilibrium. If equilibria exist, they are characterized by intermediate levels of differentiation.

We analytically establish locational equilibria for the three-firms case and numerically for game with up to nine players. They are characterized by locations symmetrically distributed around the market center, where corner firms move considerably towards the center firm(s) and prices are U-shaped.

The paper is organized as follows. In the next section the model is described. In Section 3 we demonstrate that a price equilibrium exists for all locational patterns. General analyses of equilibrium locations and explicit perfect equilibria for games with up to nine players follow in Section 4 and 5, respectively. Section 6 concludes the paper. Some of the proofs are contained in Appendix.

\section{The model}

We examine a generalized Hotelling-game with quadratic utility of customers. While d'Aspremont, Gabszewicz and Thisse (1979) consider a duopoly, we allow for an arbitrary (but fixed) number of firms. The game proceeds in two stages. In the first stage $n$ firms choose locations $\bar{x}=\left(x_{1}, x_{2}, \ldots, x_{n}\right)$ on the unit interval $[0,1]$. At the second stage, prices $\bar{p}=\left(p_{1}, p_{2}, \ldots, p_{n}\right)$ are simultaneously fixed. The firms produce a homogeneous product and sell one unit to each consumer. Consumers are equally distributed over the interval. Firms use the same constant returns to scale 
production technology. Marginal costs are normalized to zero.

Since products are homogeneous only transport costs matter for the decision from which firm to buy. Consumers are endowed with utility $u_{w}\left(x_{j}, p_{j}\right)=k-p_{j}-\left(x_{j}-w\right)^{2}$, where $x_{j}$ represents the location of firm $j$.

Consumer utility $u_{w}$ has a peak where the consumer's location $w$ and the firm's location coincide. The term $-\left(x_{j}-w\right)^{2}$ can be interpreted as the quadratic disutility which consumers incur through the distance of transport. $k>0$ is the reservation price. Only if $k$ exceeds the sum of price and transport costs does the consumer buy.

We are looking for perfect Nash equilibria in pure strategies and assume the coordination problem away. Thus, firms are exogenously assigned numbers which represent their position in the spatial order. We neglect them not only in view of the analytical challenges they introduce but also because mixed strategies are not played by people in complex situations (Rapoport and Amaldoss, 2000). Nevertheless, ignoring the coordination problem in the multi-firm setting can be regarded as a shortcoming of the model since no plausible explanations exist why and how such a formation could appear, in particular if the number of firms is large.

\section{Price equilibrium}

In order to solve for a subgame perfect equilibrium, we first consider the last stage of the game. At this stage, locations are already chosen and prices are to be posted simultaneously and non-cooperatively. To establish results on the existence and 
uniqueness of the price equilibrium, we start by examining the demand of the firms.

The purchasing decision of a consumer is determined by its position, the reservation price, the position of the firms and the prices they charge. In the duopoly case when the reservation price constraint is binding, i.e., if $u_{w}$ of some individuals located between the shops becomes negative for the price-location combination of both firms, these customers will not buy any products. Then firms become local monopolists. Let us consider the case where the reservation price is sufficiently high such that every consumer buys a unit of the product. Assuming further that each firm chooses a different location, the duopoly demand can easily be calculated by finding the consumer who is indifferent between buying from the left and from the right firm, i.e. where $u_{w}\left(x_{1}, p_{1}\right)=u_{w}\left(x_{2}, p_{2}\right)$. This individual divides the set of consumers into two convex subsets where the left subset will be supplied by the left firm and vice versa. In the multi-firm case, demand for an inside firm $j(1<j<n)$ is not necessarily the set between the marginal consumers with respect to firm $j-1$ and $j+1$. This holds because the direct neighbors may attract no demand at all by charging prohibitively high relative prices. In this case, firm $j$ competes with two of the more distant firms. However, this could never be an equilibrium because a firm with no demand would be better off lowering its price until it attracts some customers.

Assuming each firm has a positive market share, demand can be expressed as:

$$
\begin{aligned}
& D_{1,0}(\bar{p} \mid \bar{x})=\frac{p_{2}-p_{1}}{2\left(x_{2}-x_{1}\right)}+\frac{x_{1}+x_{2}}{2}, \\
& D_{j, 0}(\bar{p} \mid \bar{x})=\frac{p_{j+1}-p_{j}}{2\left(x_{j+1}-x_{j}\right)}-\frac{p_{j}-p_{j-1}}{2\left(x_{j}-x_{j-1}\right)}+\frac{x_{j+1}-x_{j-1}}{2}, \text { if } 1<j<n,
\end{aligned}
$$


$D_{n, 0}(\bar{p} \mid \bar{x})=1-\frac{p_{n}-p_{n-1}}{2\left(x_{n}-x_{n-1}\right)}-\frac{x_{n}+x_{n-1}}{2}$

Obviously, demand $D_{j, 0}$ is linear in price $p_{j} !^{3}$ Starting from a price $p_{j}^{\text {prohib }}$ at which the marginal consumer is indifferent between buying from firms $j-1, j$, and $j+1$, by successively decreasing its price an inside firm $j$ will reach a value $p_{j}^{\prime}$ at which it drives one of the neighbors out of business and starts to compete with the next firm. Then the above relationship does not hold anymore. If for example the whole demand of firm $j+1$ would have been withdrawn by firm $j$, i.e. for the marginal consumer with $u_{w}\left(p_{j+2}, x_{j+2}\right)=u_{w}\left(p_{j}, x_{j}\right)$ inequality $u_{w}\left(p_{j}, x_{j}\right)>u_{w}\left(p_{j+1}, x_{j+1}\right)$ holds, the corresponding demand relationship would be:

$$
D_{j, 1}(\bar{p} \mid \bar{x})=\frac{p_{j+2}-p_{j}}{2\left(x_{j+2}-x_{j}\right)}-\frac{p_{j}-p_{j-1}}{2\left(x_{j}-x_{j-1}\right)}+\frac{x_{j+1}-x_{j-1}}{2}, \text { if } 1<j<n
$$

This subsequent piece of the demand curve is linear too but less steep. Decreasing price $p_{j}$ further leads to the undercutting of more and more competitors until the firm has attracted all customers or $p_{j}=0$. Figure 1 shows the resulting demand curve. Undercutting of neighbors leads to kinks in this curve at prices $p_{j}^{\prime}, p_{j}^{\prime \prime}$, and $p_{j}^{\prime \prime \prime}$ where the demand of the respective neighbors is withdrawn. The resulting demand function of firm $j$ corresponds to the lower envelope of all $D_{j, k}(k=0, . ., n-1)$. Obviously, it is concave. Similarly, one obtains a concave demand curve for the corner firms. Hence, we have established:

Proposition 1 The demand function $D_{j}$ is concave with respect to the firm's price

\footnotetext{
${ }^{3}$ The second subscript denotes the number of neighbors of firm $j$ whose (potential) demand is totally withdrawn by firm $j$. In this case, even customers having the same location as those neighbor firms would rather buy from firm $j$.
} 
$p_{j}$

Kakutani's fixed point theorem can be applied to prove the existence of a noncooperative price equilibrium. Friedman (1977) shows that if the number of players is finite, the strategy set of the $i$ th player is a compact convex subset of $R^{n}$ and if the profit function is quasi-concave with respect to the own price, the fixed point theorem holds. Moreover, uniqueness of this equilibrium can be shown. Economides' (1989) proof for the circular model is easily extended to the interval model. ${ }^{4}$

\section{INSERT FIGURE 1 ABOUT HERE}

Note that up to this point configurations were neglected where some firms choose the same location. If this is the case then these firms would price their products at marginal cost because it would always pay to undercut the rival's price to attract some demand given prices are higher than marginal costs. This logic follows the well known Bertrand result. Together with the above considerations this leads to

Proposition 2 For every given pattern of locations there exists a unique equilibrium of the price setting stage.

Given each firm has a positive market share maximizing the profit function $\Pi_{j}(\bar{p} \mid \bar{x})=p_{j} D_{j, 0}(\bar{p} \mid \bar{x})$ with respect to $p_{j}$ leads to the following price reaction functions:

\footnotetext{
${ }^{4}$ Showing that $\frac{\partial^{2} \Pi_{j}}{\partial p_{j}^{2}}+\sum_{j \neq i}\left|\frac{\partial^{2} \Pi_{j}}{\partial p_{j} \partial p_{i}}\right|<0$ for all $j$ is sufficient to conclude that best replies
} are contractions and thus, that the equilibrium is unique. For interior firms, Economides' (1989) results are identical to ours. For the left corner firm (and correspondingly for the right corner firm), we find that $\frac{\partial^{2} \Pi_{1}}{\partial p_{1}^{2}}+\sum_{i \neq 1}\left|\frac{\partial^{2} \Pi_{1}}{\partial p_{1} \partial p_{i}}\right|=-\frac{1}{2\left(x_{2}-x_{2}\right)}<0$. 


$$
\begin{aligned}
& p_{1}^{*}(\bar{p} \mid \bar{x})=\left[p_{2}+\left(x_{1}+x_{2}\right)\left(x_{2}-x_{1}\right)\right] / 2, \\
& p_{j}^{*}(\bar{p} \mid \bar{x})=\frac{p_{j+1}\left(x_{j}-x_{j-1}\right)}{2\left(x_{j+1}-x_{j-1}\right)}+\frac{p_{j-1}\left(x_{j+1}-x_{j}\right)}{2\left(x_{j+1}-x_{j-1}\right)}+\frac{\left(x_{j+1}-x_{j}\right)\left(x_{j}-x_{j-1}\right)}{2}, \text { if } 1<j<n, \\
& p_{n}^{*}(\bar{p} \mid \bar{x})=\left[p_{n-1}+\left(2-x_{n-1}-x_{n}\right)\left(x_{n}-x_{n-1}\right)\right] / 2 .
\end{aligned}
$$

It is easy to verify that the system of prices is identified.

\section{No maximum, no minimum differentiation}

In the following two sections, we are concerned about the characterization of locational equilibria, given the price reaction functions of the last stage. We first attempt to characterize equilibria for games with any number of players. Because of analytical difficulties, a full characterization of location equilibria could not be achieved $5^{5}$ In this section, we show that under very general conditions, firms do neither maximize differentiation nor do they minimize differentiation. The subsequent section provides locations and prices for games with less than ten players.

For the corner firms, one may expect maximum differentiation in equilibrium, i.e. locations at the interval boundaries. This pattern is suggested by the corresponding duopoly model. We show that given any number of players larger than two, maximum differentiation in this sense would never prevail in equilibrium.

In contrast, the multi-firm model with linear disutility implies firms having al-

\footnotetext{
${ }^{5}$ Because of asymmetry between firms, the interval model with quadratic disutility is analytically less tractable than the other variants of the model examined by Economides (1989, 1993). First, in contrast to the circular models, it matters how many neighbors of a firm are located on each of its sides. Second, in contrast to the linear disutility models, it matters how large are the distances between all of the firms.
} 
ways an incentive to marginally relocate towards the central firm(s). Economides (1993) calls this behavior the "strong principle of minimum differentiation". We show that quadratic disutility destroys the possibility for minimum differentiation to be an equilibrium strategy.

In order to prove that corner firms do not maximize distance to their direct neighbors, we first show that corner firms being located at the interval boundaries possess incentives to move towards the market center, given that locations of the adjacent rivals are not too close.

Lemma 1 Given any set of locations $\bar{x}$ with $x_{1}=0$ and $x_{2} \in\left[\frac{x_{3}}{2}, x_{3}\right]$, firm 1 always has an incentive to marginally relocate towards firm 2. Correspondingly, given any set of locations $\bar{x}$ with $x_{n}=1$ and $x_{n-1} \in\left[x_{n-2}, \frac{1+x_{n-2}}{2},\right]$, firm $n$ always has an incentive to marginally relocate towards firm $n-1$.

The proof is in the appendix. Note that under the given condition, firms 3 to $n-2$ could not prevent corner firms from profitably decreasing differentiation.

Lemma 2 Given any set of locations $\bar{x}$ with $x_{1}=0$ and $x_{2}=\frac{x_{3}}{2}$, firm 2 never has an incentive to marginally relocate towards firm 1. Correspondingly, firm $n-1$ never has an incentive to marginally relocate towards firm $n$ if $x_{n}=1$ and $x_{n-1}=\frac{1+x_{n-2}}{2}$.

In lemma 2, which is proven in the appendix, we show that the corner firms' neighbors have optimal locations closer to firm $3(n-2)$ than to the respective corner firm, given $x_{1}=0\left(x_{n}=1\right)$. From lemma 1 and lemma 2 , we can derive the following proposition. 
Proposition 3 Assuming that a locational equilibrium exists for the quadratic disutility Hotelling game with $n>2$ players choosing locations $\bar{x}^{*}=\left(x_{1}^{*}, . ., x_{n}^{*}\right)$ on the unit interval, this equilibrium would never entail maximum differentiation for the corner firms, i.e. $x_{1}^{*}>0$ and $x_{n}^{*}<1$.

Lemma 1 and 2 imply something more general than actually stated in proposition 3. Even including a large set of rivals' off-the-equilibrium locations, maximum differentiation by corner firms is never a best response, given the next neighbor is not too closely located.

If interior players are present corner firms do would not maximize differentiation to their adjacent rivals. Interior firms are at a disadvantage vis-à-vis the corner firms because their prices are bound to react much softer to a marginal relocation by their neighbors. Corner firms can compete tougher in prices, and thus in locations, because price changes are confined exclusively on the "aggressor", while an interior player would also initiate responses by neighbors on the other side.

One might wonder if softer price competition of interior firms ultimately leads to minimum differentiation. Minimum differentiation would prevail if firms have in every spatial configuration a tendency to relocate marginally towards the central firms, such as in the linear disutility variant of this model (Economides, 1993). However, despite the fact that interior firms are weaker competitors than their neighbors at the interval boundaries, it is still not optimal for any firm to approach a direct neighbor too closely. We show that the equilibria do no collapse as in the corresponding game with linear disutility. 
Lemma 3 Given any set of locations $\bar{x}$, firm $i(i=2, . ., n)$ has an incentive to marginally relocate away from firm $i-1$ if $\left(x_{i}-x_{i-1}\right)$ becomes sufficiently small. Correspondingly, given any set of locations $\bar{x}$, firm $i(i=1, . ., n-1)$ has an incentive to marginally relocate away from firm $i+1$ if $\left(x_{i+1}-x_{i}\right)$ becomes sufficiently small.

From lemma 3, we can derive the following proposition.

Proposition 4 Assuming that a locational equilibrium exists for the quadratic disutility Hotelling game with $n>2$ players choosing locations $\bar{x}^{*}=\left(x_{1}^{*}, . ., x_{n}^{*}\right)$ on the unit interval, this equilibrium would not entail minimum differentiation for any of the firms, i.e. $x_{i-1}^{*}<x_{i}^{*}$ for all $i \leq n$.

The proof is in the appendix.

We have shown that some prominent locational structures can be excluded from the set of potential equilibrium strategies. Unfortunately, we still do not know which, if any, equilibria appear in the case of more than two players. This question is addressed in the following section.

\section{Locational equilibria for three to nine players}

In order to obtain explicit locational equilibrium solutions $\bar{x}^{*}=\left(x_{1}^{*}, x_{2}^{*}, \ldots, x_{n}^{*}\right)$ for the multi-firm case, explicit price reaction functions of the last stage of the game are required. As derived in Section 3, the price of a firm depends on its location, the location of its direct neighbors, and the prices they charge. Hence, prices depend indirectly on all other prices and ultimately, locations. Transforming this system of 
implicit price functions into a system of functions with only locations on the right hand side is a difficult task. Without imposing any constraints, the equation system could not be solved when the number of firms is large. The solution of the threefirms game can be obtained analytically. For games with more than three players, we applied numerical methods to find equilibria ${ }^{6}$

The solutions are shown in Figure 2. As we expect from the results of the previous section, the corner firms move considerably towards the central firms. In the threefirms case, the distance to the interval boundary is $\frac{1}{8}$. Adding firms to the market leads corner firms to locate closer to the interval end points in absolute terms. Thus, it seems that competition for the corner firms becomes fiercer as they are pushed towards the borders. However, relating the absolute distance of the corner firm to its respective interval boundary to the average distance between neighbors shows a reverse picture. The relative position of the corner firms is strengthened the more players are in the game. In the four-player case this ratio is about one half as opposed to one third in the three firms case. Games with five to nine players lead to only weakly increasing ratios of about 0.53 . Thus apparently the pressure for the corner firms to differentiate decreases in relative terms with the number of firms since price competition is softened at the same time.

\footnotetext{
${ }^{6}$ Besides verifying that first and second order conditions of the profit functions are fulfilled, providing that the solution represents a local profit maximum, we excluded an instability of the pattern with respect to larger steps of relocation by making sure that it would not pay off for any firm to change the position along the interval limited by its direct neighbors' locations (leap-frogging). In particular, it is shown numerically that $\frac{d^{2} \Pi_{j}\left(p^{*}\left(x_{j}, x_{-j}^{*}\right), x_{j} \mid x_{-j}^{*}\right)}{d x_{j}^{2}}<0$ for $x_{j} \in\left[x_{j-1}^{*}, x_{j+1}^{*}\right]$, if $1<j<n$, and for $x_{1} \in\left[0, x_{2}^{*}\right]$ and $x_{n} \in\left[x_{n-1}^{*}, 1\right]$, otherwise.
} 


\section{INSERT FIGURE 2 ABOUT HERE}

How distant is the social optimum away from the corresponding equilibrium? Would there be identical prices, the socially optimal outcome would require that succeeding firms have equal distance and corner firms locate one half of this stretch away from the interval boundaries. This configuration would minimize transport costs. However, equilibrium prices are U-shaped $\sqrt[7]{7}$ Taking the distorting price effect into account, we find too much differentiation if $n=3$ and too less differentiation for $n>3$. The reason is that the degree of price competition is the less intense the higher is the number of firms. As the relative power of the corner firm increases with an rising number of firms, the market becomes more squeezed.

\section{INSERT TABLE 1 ABOUT HERE}

Table 1 shows that equilibrium profits decrease with the number of firms. This is due to the increase of price competition induced by additional competitors. More interestingly, the relative increase of market power enjoyed by the corner firms following an increase of the number of rivals is also reflected in the firms' profits. In the three-firm case the equilibrium profit of the center firm considerably exceeds the corner firms' profits. In this case, because the center firm is not as weak a price competitor as were there more interior firms, a higher number of consumers attracted by the center firm compensates for the lower price. When four players compete, profits are almost equally distributed while in the oligopoly with five or

\footnotetext{
${ }^{7}$ In such an equidistant setting, prices would be U-shaped too. The proof is available from the author.
} 
more players central firms earn much less than their corner rivals. Although the center firm finds itself in an uncomfortable position, there is no higher profitable market niche to relocate to 8

\section{Conclusions}

We analyzed the multi-firm unit interval Hotelling model under quadratic transport costs. Firms choose locations in the first stage and prices in the second stage of the game. Existence and uniqueness of the short run price game is established. In contrast to the results for the similar circular model and the duopoly interval model it has been shown that the principle of maximum differentiation does not hold. Under very general conditions, including any possible equilibrium configurations, corner firms would benefit from moving marginally towards their adjacent rivals. Equally the (strong) principle of minimum differentiation such as established for the similar multi-firm game with linear transport costs (Economides, 1993) does not hold. Firms would never choose the same location as a best response to location choices by their rivals. A fortiori, no equilibrium would entail minimum differentiation. Given that a perfect equilibrium exists, it corresponds to an in-between differentiation

\footnotetext{
${ }^{8}$ It cannot be excluded that this might change as the number of firms grows. Positions between the boundary and the corner firm or between the corner and its neighbor firm may provide a region large enough to be more profitable than the center location if the number of firms exceeds nine. Then subgame perfect equilibria may not be identified by local first and second order conditions alone which makes the search for them more difficult or even destroys the possibility for a perfect equilibrium.
} 
configuration.

Explicit perfect equilibria are calculated for games with up to nine firms. They are characterized by a U-shaped price structure and corner firms which are located inside the interval. The distance between the corner firms and their direct neighbors is larger than the distances between the interior firms. This follows from an asymmetry in price competition. Introducing interior firms creates asymmetry in the game regarding the willingness of firms to cut prices as a response to marginal relocations by their neighbors. A price cut by an interior firm would not only affect the aggressive rival but the remaining firms too (in contrast to price cuts by corner firms). This externality makes an interior firm a weaker competitor. The resulting increase of "relative" market power together with an increase of overall competition leads to lower absolute but higher relative profits of the corner firms. Further, the competitive advantage of the corner firms is partially transferred to their neighbors which is reflected in higher prices of firms close to the market boundaries.

Viewed from the welfare perspective, we find too much differentiation if $n \leq 3$. Increasing the number shifts relatively more power to the corner firms which use this power to squeeze their inside rivals. Interior firms become softer rivals. This leads to a level of differentiation below the social optimum for $n>3$.

How does the number of firms influence the equilibrium outcome of Hotelling games? Comparing our results with the studies by Salop (1979) and Economides (1989, 1993), it seems that increasing the number of firms has three effects. First, price equilibrium is not endangered. For the quadratic transport costs model, a Nash equilibrium exists for the duopoly as well as for the oligopoly variant. Assuming 
linear transport costs, price equilibria exist for the multi-firm case in symmetric configurations, while it does not exist in the duopoly case. Second, introducing a market boundary leads to asymmetry between firms with interior firms becoming weaker price competitors. For multi-firm interval models under linear transport costs, the existence of interior firms leads to minimum differentiation. In this paper, we show that it destroys maximum differentiation as an equilibrium under quadratic transport costs. Third, given a market boundary, corner firms enjoy greater market power than their inside competitors. This is reflected in a U-shaped price structure in linear market models, and in larger than average distances between corner firms and their direct neighbors in the particular quadratic disutility model.

\section{A Appendix}

Proof of Lemma 1. Mathematically, we have to show that $\frac{d \Pi_{1}(\bar{x})}{d x_{1}}>0$ for any $\bar{x}=\left(x_{1}, . ., x_{n}\right)$ with $x_{1}=0$ and $x_{2}=\frac{x_{3}(1+\alpha)}{2}, 0 \leq \alpha \leq 1$.

Using the implicit price functions for firm 1 and 2 as derived in Section 3, and making use of lemma 4 for the representation of $p_{3}$, i.e. $p_{3}=c_{3}\left(x_{2}, . ., x_{n}\right) p_{2}+$ $d_{3}\left(x_{2}, . ., x_{n}\right)$ we obtain $\frac{d \Pi_{1}(\bar{x})}{d x_{1}}=$

$$
p_{1} \frac{x_{3}^{2}\left(20+46 \alpha-2 \alpha^{3}+2(1+\alpha)^{3} c_{3}^{2}-(1+\alpha)(17+3 \alpha(4+\alpha))\right) c_{3}+4 d_{3}\left(1+7 \alpha-2(1+\alpha) c_{3}\right)}{2(1+\alpha) x_{3}^{2}\left(7+\alpha-2(1+\alpha) c_{3}\right)^{2}}>0 \text { with } c_{3} \leq \frac{1}{2},
$$

and $d_{3} \geq 0$. The proof for firm $n$ works analogously.

Proof of Lemma 2. Again, because of symmetric properties of the problems, we concentrate on the case of the left firm . We have to show that $\frac{d \Pi_{2}(\bar{x})}{d x_{2}} \geq 0$ for any $\bar{x}=\left(x_{1}, . ., x_{n}\right)$ with $x_{1}=0$ and $x_{2}=\frac{x_{3}}{2}$. Using implicit price functions for $p_{1}$, 
$p_{2}$ and $p_{3}$ as derived in Section 3 and lemma 4 for the representation of $p_{4}$, with $p_{4}=$ $c_{4}\left(x_{3}, . ., x_{n}\right) p_{3}+d_{4}\left(x_{3}, . ., x_{n}\right)$ we obtain $\frac{d \Pi_{2}(\bar{x})}{d x_{2}}=p_{2} \frac{4\left(2-c_{4}\right)\left(24\left(d_{4}+\left(x_{4}-x_{3}\right)^{2}\right)+24 x_{3}\left(x_{4}-x_{3}\right)+\left(2-c_{4}\right) x_{3}^{2}\right)}{\left(24\left(x_{4}-x_{3}\right)+7\left(2-c_{4}\right) x_{3}\right)^{2}}$.

With $0 \leq d_{4} \leq \frac{1}{2}$ and $c_{4} \geq 0$, it is easy to see that $\frac{d \Pi_{2}(\bar{x})}{d x_{2}}>0$. For the three-firms case, $\frac{d \Pi_{2}(\bar{x})}{d x_{2}}=0$ can be easily derived.

Proof of Lemma 3. We first show that lemma 3 holds for the corner firms. Given the implicit price functions of firm 1 and 2 such as presented in Section 3 and using lemma 4 for the representation of $p_{3}$ similarly as in lemma 1 and lemma 2 , we show for any $\bar{x}=\left(x_{1}, . ., x_{n}\right)$ with $x_{1}=x_{2}-\varepsilon$, that $\frac{d \Pi_{1}(\bar{x})}{d x_{1}}<0$ and $\frac{d \Pi_{2}(\bar{x})}{d x_{2}}>0$ if $\varepsilon$ becomes sufficiently small. We obtain

$$
\begin{gathered}
\frac{d \Pi_{1}(\bar{x})}{d x_{1}}=\frac{p_{1}}{2\left(\varepsilon-2 c_{3} \varepsilon+3\left(x_{3}-x_{1}\right)\right)^{2}}\left(\frac{-3\left(x_{3}-x_{1}\right)\left(d_{3}+\left(x_{3}-x_{1}\right)\left(x_{3}+3 x_{1}\right)\right)}{\varepsilon}+z_{11}+\varepsilon z_{12}+\varepsilon^{2} z_{13}\right) \text { and } \\
\frac{d \Pi_{2}(\bar{x})}{d x_{2}}=\frac{p_{2}}{2\left(\varepsilon-2 c_{3} \varepsilon+3\left(x_{3}-x_{1}\right)\right)^{2}\left(\varepsilon+x_{1}-x_{3}\right)^{2}}\left(\frac{6\left(x_{3}-x_{1}\right)^{3}\left(d_{3}+x_{3}\left(x_{3}-x_{1}\right)\right)+z_{21} \varepsilon+z_{22} \varepsilon^{2}+z_{23} \varepsilon^{3}+z_{24} \varepsilon^{4}+z_{25} \varepsilon^{5}}{\varepsilon}\right),
\end{gathered}
$$

with $z$ being terms which do not depend on $\varepsilon$.

Similarly, we have to show that, given any location configuration, an interior firm $i$ would move away from a direct neighbor if the distance between them becomes too small. It is sufficient to show that this holds between a firm and one of its neighbors. We use lemma 4 to express prices $p_{i+1}=c_{i+1}\left(x_{1}, . ., x_{i}\right) p_{i}+d_{i+1}\left(x_{1}, . ., x_{i}\right)$ and $p_{i-1}=$ $a_{i-1}\left(x_{i}, . ., x_{n}\right) p_{i}+b_{i-1}\left(x_{i}, . ., x_{n}\right)$. Calculating the first order profit condition for firm $i$ with $x_{i-1}=x_{i}-\varepsilon$, we obtain

$$
\frac{d \Pi_{i}(\bar{x})}{d x_{1}}=A\left(\frac{\left(x_{i}-x_{i-1}\right)^{3}\left(2-a_{i-1}\right)\left(\left(x_{i}-x_{i-1}\right)^{2}+\frac{b_{i-1}}{\varepsilon}\left(x_{i}-x_{i-1}\right)+d_{i+1}\right)+z_{1} \varepsilon+z_{2} \varepsilon^{2}+z_{3} \varepsilon^{3}+z_{4} \varepsilon^{4}}{\varepsilon}\right),
$$

with $A=\frac{p_{i}}{2\left(x_{i}-x_{i-1}\right)^{2}\left(2\left(x_{i}-x_{i-1}+\varepsilon\right)-a_{i-1}\left(x_{i}-x_{i-1}\right)-\varepsilon c_{i+1}\right)^{2}}$ and $z$ being terms which do not depend on $\varepsilon$. Thus, since obviously $\frac{d \Pi_{i}(\bar{x})}{d x_{1}}>0$ for sufficient close locations of firm $i-1$ and firm $i$, there would be an incentive for firm $i$ to marginally move away. With the same logic, we can prove that firm $i-1$ would have an incentive to 
marginally move away from firm $i$, provided locations are sufficiently close.

Lemma 4 The price of firm $i<n$ can be expressed as $p_{i}=a_{i}\left(x_{1}, . ., x_{i+1}\right) p_{i+1}+$ $b_{i}\left(x_{1}, . ., x_{i+1}\right)$, with $0 \leq a_{i} \leq \frac{1}{2}$ and $b_{i} \geq 0$. Similarly, the price of firm $i>1$ can be expressed as $p_{i}=c_{i}\left(x_{i-1, . .}, x_{n}\right) p_{i-1}+d_{i}\left(x_{i-1, \cdot .}, x_{n}\right)$, with $0 \leq c_{i} \leq \frac{1}{2}$ and $d_{i} \geq 0$.

Proof of Lemma 4. Proof is by complete induction. We start with the first part of lemma 4. It obviously holds for $i=n$ (see implicit price functions in Section 3). If $i<n$, the implicit price function of firm $i$ is given by

$$
p_{i}=p_{i-1} \frac{\left(x_{i+1}-x_{i}\right)}{2\left(x_{i+1}-x_{i-1}\right)}+p_{i+1} \frac{\left(x_{i}-x_{i-1}\right)}{2\left(x_{i+1}-x_{i-1}\right)}+\frac{\left(x_{i+1}-x_{i}\right)\left(x_{i}-x_{i-1}\right)}{2} .
$$

Given that $p_{i-1}=a_{i-1} p_{i}+b_{i-1}$ with $a_{i-1} \leq \frac{1}{2}$ and $b_{i-1} \geq 0$, we can write $p_{i}$ as

$$
p_{i}=p_{i+1} \frac{\left(x_{i}-x_{i-1}\right)}{2\left(x_{i+1}-x_{i-1}\right)-a_{i-1}\left(x_{i+1}-x_{i}\right)}+\frac{\left(x_{i+1}-x_{i}\right)\left(\left(x_{i+1}-x_{i-1}\right)\left(x_{i}-x_{i-1}\right)+b_{i-1}\right)}{2\left(x_{i+1}-x_{i-1}\right)-a_{i-1}\left(x_{i+1}-x_{i}\right)} .
$$

With $x_{i-1} \leq x_{i} \leq x_{i+1}$, it is easy to see that $0 \leq a_{i}=\frac{\left(x_{i}-x_{i-1}\right)}{2\left(x_{i+1}-x_{i-1}\right)-a_{i-1}\left(x_{i+1}-x_{i}\right)} \leq \frac{1}{2}$ and

$$
b_{i}=\frac{\left(x_{i+1}-x_{i}\right)\left(\left(x_{i+1}-x_{i-1}\right)\left(x_{i}-x_{i-1}\right)+b_{i-1}\right)}{2\left(x_{i+1}-x_{i-1}\right)-a_{i-1}\left(x_{i+1}-x_{i}\right)} \geq 0 \text {. The second part of lemma } 4 \text { holds }
$$
because of symmetry of the problems. 


\section{References}

Balvers, Ronald, and Laszlo J. Szerb. 1996. "Location in the Hotelling Duopoly Model with Demand Uncertainty," European Economic Review, 40, $1453-1461$.

Bester, Helmut, André de Palma, Wolfgang Leininger, Jonathan Thomas, and Ernst-Ludwig von Thadden. 1996. "A Noncooperative Analysis of Hotelling's Location Game," Games and Economic Behavior, $12,165-186$.

Böckem, Sabine. 1994. "A Generalized Model of Horizontal Product Differentiation," Journal of Industrial Economics, 42, 287-298.

D'Aspremont, Claude, Jean Jaskold Gabszewicz, and JacquesFrançois Thisse. 1979. "On Hotelling's Stability in Competition," Econometrica, 47, 1145-1150.

Economides, Nicolas. 1986. "Minimal and Maximal Product Differentiation in Hotelling's Duopoly," Economics Letters, 21, 67-71.

(1989): "Symmetric Equilibrium Existence and Optimality in Differentiated Product Markets," Journal of Economic Theory, 47, 178-194.

(1993): "Hotelling،s "Main Street" with More Than Two Competitors," Journal of Regional Science, 33(3), 303-319. 
Friedman, James W. 1977. Oligopoly and the Theory of Games. North-Holland, Amsterdam.

Fujita, Masahisa, And JaCques-François Thisse. 1986. "Spatial Competition with a Land Market: Hotelling and Von Thunen Unified," Review of Economic Studies, 53, 819-841.

Hinloopen, Jeroen, and Charles MarrewiJk. 1999. "On the Limits and Possibilities of the Principle of Minimum Differentiation," International Journal of Industrial Organization, 17, 735-750.

Hotelling, Harold. 1929. "Stability in Competition," The Economic Journal, 3, $41-57$.

Mai, Chao-Cheng, and Shin-Kun Peng. 1999. "Cooperation Vs. Competition in a Spatial Model," Regional Science and Urban Economics, 29, 463-472.

Neven, Damien. 1985. "Two Stage (Perfect) Equilibrium in Hotelling's Model," Journal of Industrial Economics, 33, 317-325.

Neven, Damien. 1986. “On Hotelling's Competition with Non-Uniform Customer Distributions," Economics Letters, 21(2), 121-126.

NovsheK, William. 1980. "Equilibrium in Simple Spatial (or Differentiated Product) Models," Journal of Economic Theory, 22, 313-326.

Rapoport, Amnon, and Wilfred Amaldoss. 2000. "Mixed Strategies and Iterative Elimination of Strongly Dominated Strategies: An Experimental Investi- 
gation of States of Knowledge," Journal of Economic Behavior and Organization, 42(4), 483-521.

Salop, Steven C. 1979. "Monopolistic Competition with Outside Goods," Bell Journal of Economics, 10, 141-156. 


\begin{tabular}{|l|l|l|l|l|l|l|l|l|l|}
\hline firms & Firm 1 & Firm 2 & Firm 3 & Firm 4 & Firm 5 & Firm 6 & Firm 7 & Firm 8 & Firm 9 \\
\hline three & 0.0550 & 0.0787 & 0.0550 & - & - & - & - & - & - \\
four & 0.0209 & 0.0219 & 0.0219 & 0.0209 & - & - & - & - & - \\
five & 0.0113 & 0.0105 & 0.008 & 0.0105 & 0.0113 & - & - & - & - \\
six & 0.0068 & 0.0063 & 0.0043 & 0.0043 & 0.0063 & 0.0068 & - & - & - \\
seven & 0.0044 & 0.0041 & 0.0028 & 0.0025 & 0.0028 & 0.0041 & 0.0044 & - & - \\
eight & 0.0030 & 0.0028 & 0.0024 & 0.0017 & 0.0017 & 0.0024 & 0.0028 & 0.0030 & - \\
nine & 0.0022 & 0.0020 & 0.0013 & 0.0012 & 0.0012 & 0.0012 & 0.0013 & 0.0020 & 0.0022 \\
\hline
\end{tabular}

Table 1: Equilibrium profits 